\title{
Left occipital craniotomy for resection of falcotentorial meningioma
}

\author{
William T. Couldwell, MD, PhD
}

Department of Neurosurgery, Clinical Neurosciences Center, University of Utah, Salt Lake City, Utah

\begin{abstract}
A 49-year-old man presented with headache and cognitive difficulty. MRI demonstrated a meningioma in the falcotentorial region with compression of the internal cerebral veins, basal veins of Rosenthal, and vein of Galen. It was a removed via a left-sided occipital interhemispheric approach, performed with the patient in the lateral position. After tumor debulking and removal of its attachment to the tentorium and anterior falx, the tumor was resected. All venous structures were preserved. The video demonstrates the technical nuances and strategy for removal of tumors in a region with complicated venous anatomy that must be preserved.
\end{abstract}

The video can be found here: https://youtu.be/wKqAn3dYu4E.

KEYWORDS meningioma; falcotentorial; interhemispheric approach; skull base

SUBMITTED June 1, 2017. ACCEPTED June 28, 2017.

INCLUDE WHEN CITING Published online October 1, 2017; DOI: http://thejns.org/doi/abs/10.3171/2017.10.FocusVid.17358.

CORRESPONDENCE William T. Couldwell, Department of Neurosurgery, Clinical Neurosciences Center, University of Utah, 175 N Medical Drive East, Salt Lake City, UT 84132. email: neuropub@hsc.utah.edu. 